\title{
A Praia Fluvial de Luzimangues, Porto Nacional (TO): um estudo do perfil socioeconômico dos visitantes
}

\section{The Beach River of Luzimangues, Porto Nacional (TO, Brazil): a study of the socioeconomic profile of visitors}

\author{
Maria do Bonfim Cavalcante Santana, Rosane Balsan
}

\section{RESUMO}

A praia de Luzimangues está localizada no município de Porto Nacional Tocantins. No Estado do Tocantins há várias formas de lazer das quais se destaca aquelas denominado de "praias fluviais". Nestes locais são implantadas infraestrutura para atrair os visitantes. Em função da construção da UHE Luis Eduardo Magalhães surgiu várias praias artificiais, denominado de "praias fluviais", entre as quais a do distrito de Luzimangues, que serviu de referência para este trabalho de conclusão de curso. Assim o presente estudo teve como objetivo geral traçar o perfil socioeconômico dos visitantes que frequentaram a praia de Luzimangues durante a temporada de 2014. As informações foram obtidas por meio de aplicação de questionários junto aos visitantes. Como resultado principal pode-se observar que, grande parte dos frequentadores foram classificados como excursionista. Apesar do turismo não ser a principal atividade econômica do município, ele contribui com a geração de emprego, renda e alimentação para um determinado grupo social.

KEYWORDS: Turismo; Visitantes; Praias fluviais; Praia de Luzimangues, Porto Nacional (TO).

\begin{abstract}
The beach Luzimangues is located in the city of Porto Nacional - Tocantins. In the state of Tocantins there are several forms of leisure of which highlights those labeled "River Beaches". These local infrastructures are deployed to attract visitors. Depending on the construction of UHE Luiz Eduardo Magalhães came several artificial beaches, called "River Beaches", including the Luzimangues district, which served as a reference for this course conclusion work. Thus the present study aimed to trace the socioeconomic profile of visitors who attended beach Luzimangues during the season of 2014. The information was obtained through questionnaires with visitors. The main result can be seen that, most of the patrons were classified as tripper. Although tourism is not the main economic activity of the municipality, it contruibutes with the generation of employment, income and food for a particular social group.
\end{abstract}

KEYWORDS: Tourism; Visitors; River Beaches; Luzimangues Beach; Porto Nacional. 


\section{Introdução}

Nos últimos anos, a atividade turística tem se apresentado como um fenômeno mundial, situado entre as principais atividades geradoras de riqueza do País. A atividade turística acontece por meio da ocupação do espaço e apropriação do meio ambiente.

De acordo com estudos realizados pela Organização Mundial do Turismo (OMT) (2003, apud SOUSA, 2012) definem o turismo como atividades de pessoas que viajam e permanecem em lugares fora de seu ambiente habitual por não mais de um ano consecutivo para lazer, negócios e outros objetivos.

O turismo, de acordo com Torre (1992, apud LEONEL, 2002), é considerado como um fenômeno social que consiste no deslocamento voluntário e temporário de indivíduos ou grupos de pessoas que, por motivos de recreação, descanso ou cultura, saem de seu local de residência habitual para outro, no qual não exercem nenhuma atividade lucrativa nem remunerada, gerando múltiplas inter-relações de importância social, econômica e cultural.

Dentre os elementos naturais que são utilizados para 0 desenvolvimento de atividades de lazer e recreação, segundo a Agência Nacional de Águas (BRASIL, 2005) estão á água, o mar, os rios e os reservatórios. Estes são alguns exemplos de ambientes explorados pelo turismo, e que geralmente não possuem programas de monitoramento e conservação que possam garantir a segurança dos visitantes e ao mesmo tempo, a integridade dos ambientes naturais onde a atividade ocorre.

Uma vez que, para compreender melhor a questão socioeconômica dos visitantes, os julgamentos dos sujeitos em relação à essa praia, buscouse identificar os mesmos quanto às categorias: turista, residente ou excursionista. Para fins desta pesquisa, faz-se necessário conhecer os aspectos sociais e econômicos da atividade turística no distrito de Luzimangues, município de Porto Nacional - TO. Cabe salientar que a operacionalização desta pesquisa ocorreu através de pesquisa bibliográfica, de campo e análise dos dados, que coletados pelos alunos participantes do projeto Rondon Tur Ambiental da praia de Porto Real no ano de 2014.

O objetivo geral desta pesquisa foi traçar o perfil socioeconômico dos visitantes e moradores da praia do distrito de Luzimangues localizada no reservatório da UHE de Lajeado, Porto Nacional - TO, durante a temporada de praia, que foi alcançado através dos seguintes objetivos específicos: Realização de análise referente à questão socioeconômica dos visitantes; Identificação dos visitantes em relação à turista, residente ou excursionista; Avaliação da opinião dos visitantes a respeito da infraestrutura da praia e do distrito de Luzimangues.

Os impactos econômicos e sociais, gerados a partir da construção de Usinas Hidrelétricas, vêm sendo cada vez mais questionados, mas é necessário conhecer também, os aspectos sociais, econômicos e culturais dos visitantes da área em estudo, para que seja possível a proposição de mudanças na comunidade local. Assim, esta pesquisa busca também, 
contribuir para a compreensão e organização espacial das dinâmicas sociais e naturais.

Para o desenvolvimento desta pesquisa, inicialmente, foi realizada uma pesquisa bibliográfica acerca da temática do turismo em reservatórios de hidrelétricas, sendo a área localizada no distrito de Luzimangues, município de Porto Nacional - TO. Foi realizado levantamento de dados sobre a área em estudo, na tentativa de fornecer um embasamento teórico sobre o tema abordado, buscando assim referências, instrumentos legais e experiências locais na técnica de levantamento de dados.

A pesquisa foi realizada por meio da observação direta percorrendo toda a praia do distrito de Luzimangues. A coleta de dados foi realizada no dia 02 de agosto de 2014, através da aplicação de 66 questionários, por meio das quais foi possível classificar, cada visitante como: residente, turista e excursionista. Também foram utilizadas fichas para avaliação do distrito de Luzimangues com informações sobre a infraestrutura do local.

Após a coleta de dados, foi realizada a sua tabulação e quantificação, utilizando a planilha eletrônica Microsoft Excel. Posteriormente, realizou-se a representação dos dados por meio da elaboração de tabelas para auxiliar na interpretação e analise dos resultados e elaboração do trabalho de conclusão de curso e defesa do mesmo.

\section{Caracterização da área}

Localizado na região norte do Brasil, Porto Nacional (TO), não é diferente de outras cidades do estado, tendo um potencial muito grande a ser explorado na área do turismo, o mesmo proporciona oportunidades de investimentos na estrutura turística.

Mediante essa problemática, surgiu à presente investigação na praia de Luzimangues que está na sua segunda temporada de praia. A mesma foi inaugurada em maio de (2013), recebeu toda estrutura com palco, tendas, barracas de alimentação e promoção de shows musicais.

Diante disso, pode-se observar que os impactos diretos nas áreas econômicas e sociais, gerados a partir da construção de Usina Hidrelétrica (UHE) vêm sendo cada vez mais questionada. Percebe-se a pouca utilização e ate mesmo, a rejeição ao uso da represa como forma de lazer pelos habitantes da cidade (SOUSA, 2012).

A partir desse eixo reflexivo, pressupõe-se que, o turismo pode se desenvolver em Luzimangues, desde que se construa um discurso favorável e otimista por parte da população receptora, formando se um meio de propagar o uso do turismo no distrito (SOUSA, 2012).

Tendo em vista que, em Luzimangues município de Porto Nacional (TO), os estudos destinados à atividade turística ainda está iniciando, sendo assim esta pesquisa busca outro fator que é o interesse pessoal de estudar a praia fluvial. 
De modo geral, esta pesquisa visa conhecer os aspectos sociais, econômicos e culturais dos visitantes da praia fluvial de Luzimangues distrito de Porto Nacional (TO).

Os resultados deste trabalho poderão servir de base para iniciar outros estudos direcionados ao turismo e, até mesmo, incentivar uma futura promoção turística, de modo que possa integrar os atrativos turísticos naturais e artificiais existentes em Luzimangues, bem como atrair investimentos voltados para os tipos de turismo que deem retorno, quer seja no mercado atual, quer seja no mercado futuro.

O distrito de Luzimangues está localizado no município de Porto Nacional - TO, na porção leste do reservatório da Usina Hidrelétrica Luiz Eduardo Magalhães, conforme o mapa de localização abaixo (Figura 1). $O$ distrito vem sendo ocupado desde a primeira metade do século XIX,com uma distribuição esparsa pelo cerrado de propriedades rurais voltadas á agricultura de subsistência e á criação de gado. Posteriormente a localidade aparece descrita como "Mangues", e assume mais recentemente a denominação de "Luzimangues", fusão dos nomes dos rios Santa Luzia e Mangues (PINTO, 2014).

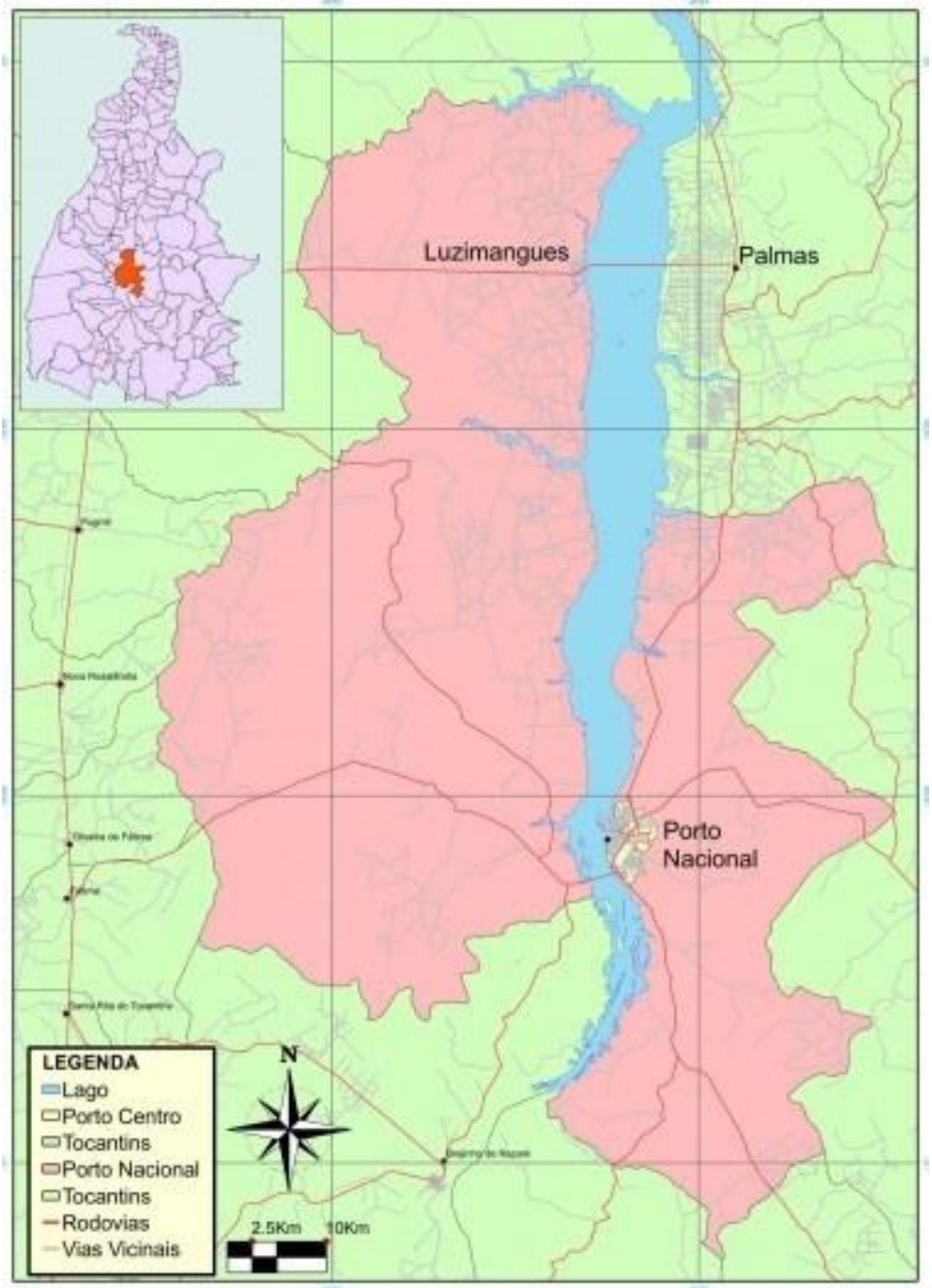

Figura 1: Mapa de localização do distrito de Luzimangues. Fonte: Pinto (2014).

Figure 1: Luzimangues district map location. Source: Pinto (2014). 
Com base nos dados mais recentes do censo 2010, o distrito de Luzimangues conta com um total de 809 domicílios particulares e coletivos, abrangendo tanto a área urbana como a rural, sendo a população total de 2.310 habitantes.

O distrito de Luzimangues, município de Porto Nacional, possui uma proximidade muito grande com a capital Palmas - correspondendo à travessia de $8 \mathrm{~km}$ da Ponte da Amizade e da Integração em 2002. Essa proximidade física faz com que seus moradores dependam mais da rede de serviços da capital do que da sede do município de Porto Nacional, distante mais de $60 \mathrm{~km}$ veja a figura abaixo (Figura 2).

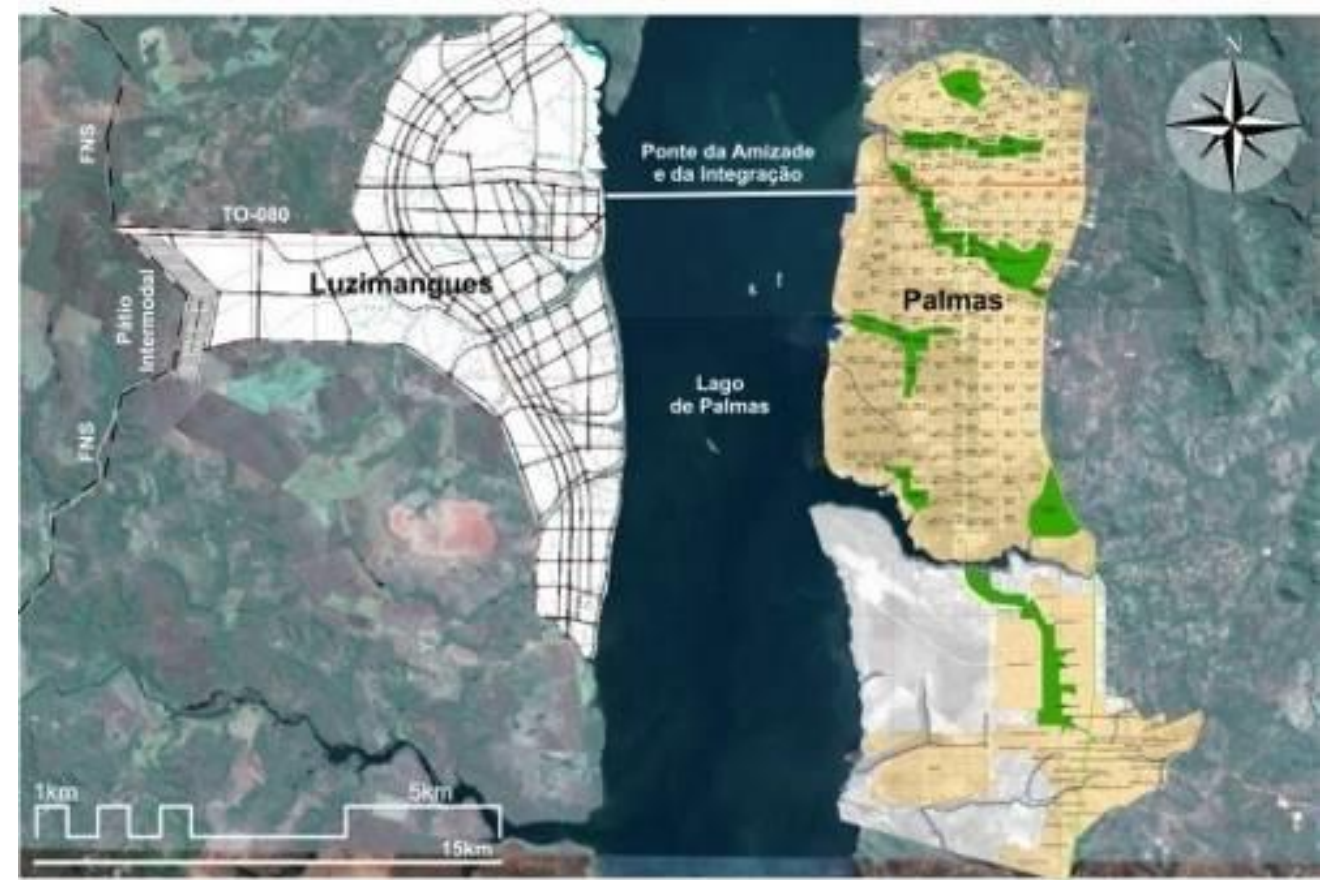

Figura 2: Perímetro urbano de Luzimangues e de Palmas. Fonte: Pinto (2014). Figure 2: City line of Luzimangues and Palmas. Source: Pinto (2014).

Com relação ao enchimento do reservatório da UHE Lajeado (ou Usina Hidrelétrica de Luís Eduardo Magalhães) localizado na bacia hidrográfica do rio Tocantins, iniciou-se em setembro de 2001, só encerando em fevereiro de 2002. De acordo com Reis Pereira apud Marques et al (2009), o reservatório ocupa uma área de $630 \mathrm{~km}$ e possui a extensão de $172 \mathrm{~km}$. Tendo em seu entorno os seguintes municípios: Miracema do Tocantins, Lajeado, Palmas, Porto Nacional, Brejinho de Nazaré e Ipueiras.

Ali foram construídas várias praias artificiais, como a de Porto Real, e a de Porto Luzimangues em Porto Nacional, a do Prata e a da Graciosa, em Palmas. Antes da formação dessas praias artificiais, existiam, em alguns locais dessa região, praias temporárias, formadas na estação seca, quando o nível do rio se apresentava baixo, surgiam extensos bancos de areia. Normalmente, esses locais eram utilizados para turismo durante o mês de julho.

Por sua vez, as praias artificiais constituem estruturas permanentes de lazer e recreação, construídas a partir da formação do reservatório, no intuito 
de substituir as praias naturais anteriormente existentes nessas localidades. MARQUES et al. (2009).

Dentre as formas de lazer no Estado de Tocantins, destaca-se aquela denominada de "praias fluviais", que se caracteriza pelo uso das margens dos rios para a implantação de uma infraestrutura, por parte do Poder Público Municipal e, ou Estadual, composta fundamentalmente por bares, restaurantes, banheiros, palcos para shows e quadras esportivas, a fim de propiciar entretenimento ao público em ambiente ribeirinho (BRITO, 2002).

Durante os meses de junho a setembro, quando há redução das chuvas, ocasionando o período de estiagem, ocorre a formação de bancos de areia nos rios que banham o Estado de Tocantins, dando origem às "praias fluviais" Sousa, (1999 apud BRITO, 2001).

$\mathrm{Na}$ verdade, é um empreendimento em que são usadas, geralmente, ambas as margens dos rios para implantação de uma infraestrutura básica, a qual viabiliza o entretenimento aos visitantes. Sendo assim, a praia de Luzimangues pode ser considerada uma praia fluvial (Figuras 3 e 4).

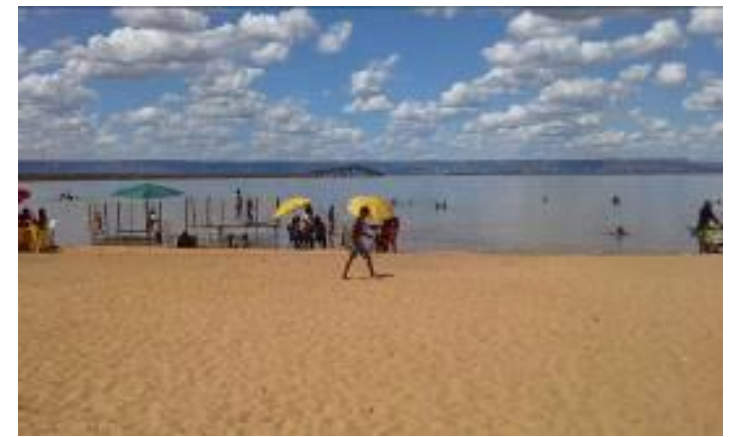

Figura 3: Praia fluvial de Luzimangues, Porto Nacional (TO) em agosto de 2014. Fonte: Rosane Balsan (2014).

Figure 3: River beach of Luzimangues, Porto Nacional (TO) in August 2014.

Source: Rosane Balsan (2014).

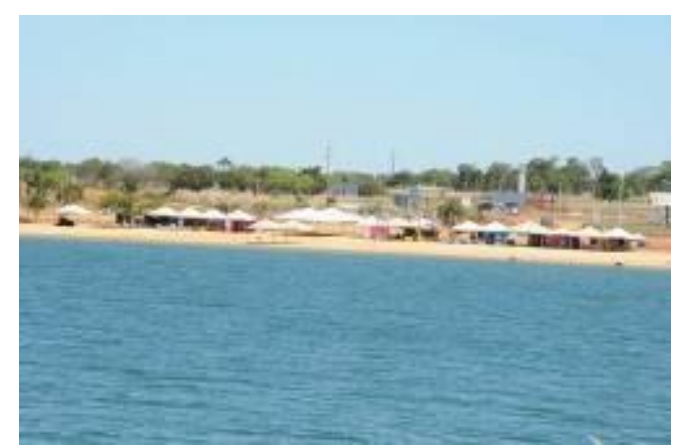

Figura 4: Vista parcial da infraestrutura da praia de Luzimangues, Porto Nacional (TO). Fonte: Rosane Balsan (2014).

Figure 4: Partial view of the infrastructure of the beach Luzimangues, Porto Nacional (TO). Source: Rosane Balsan (2014).

\section{Os Planos Nacionais de Turismo no Brasil}

No Brasil, o órgão público responsável pelo planejamento e desenvolvimento do turismo é o Ministério do Turismo. Criado em 2003, no governo do presidente Luís Inácio Lula da Silva, este órgão surge com a missão de desenvolver o turismo como uma atividade econômica sustentável, com importante atuação na geração de empregos e divisas, proporcionando assim a inclusão social (BRASIL, 2004).

Este Ministério é composto por duas secretarias nacionais (Secretaria Nacional de Políticas do Turismo - SNPT-MTur e Secretaria Nacional de Programas de Desenvolvimento do Turismo - SNPDT-MTur) e a EMBRATUR - Instituto Brasileiro de Turismo (BRASIL, 2004). Segundo o MTur a SNPT-Mtur é responsável pela política nacional relativa ao setor de acordo com as diretrizes estabelecidas pelo Conselho Nacional do Turismo. 
É também responsável pela promoção interna e pelas questões relacionadas à qualidade da prestação do serviço turístico brasileiro. A estratégia de regionalização dos produtos turísticos nos estados brasileiros é uma das metas desta Secretaria.

Já a Secretaria Nacional de Programas de Desenvolvimento do Turismo - SNPDT-MTur tem como principal função o desenvolvimento da infraestrutura em localidades turísticas ou com potencial turístico e a melhoria da qualidade dos serviços prestados ao setor turístico (BRASIL, 2004).

A EMBRATUR, antiga Empresa Brasileira de Turismo foi reformulada com o surgimento do MTur e tornou-se o Instituto Brasileiro de Turismo. Esta autarquia foi criada em 18 de novembro de 1966, com a função de fomentar a atividade, gerar empregos no setor turístico e desenvolver a atividade em todo o Brasil, (BRASIL, 2004).

\section{Turismo e a Atividade Turística}

O turismo é transformador do espaço em que está presente. O fenômeno turístico impõe relações de usos e apropriações do território e se torna "produto do sistema capitalista, que consome espaços culturais e naturais, além de modificá-los, e proporcionar mudanças constantes entre $o$ homem e o meio, em nível social, territorial, psicológico" (MASSARUTTO; VIEIRA, 2005).

A abordagem do turismo enquanto uma atividade modificadora do espaço aponta para uma definição humana da atividade, conforme Moesch, (2002) "[...] o turismo é o processo humano, ultrapassa o entendimento como função de um sistema econômico".

E a atividade turística como prática social tende a abranger os limites sócio espaciais das localidades onde está presente. Por isso a diversidade do espaço tende a entender o turismo como uma pratica social, econômica, política, cultural e educativa, envolvendo relações sociais e de poder entre residentes e turistas, produtores e consumidores (CORIOLANO, 2007).

Desta forma o turismo pode ser interpretado como uma ligação social que envolve a comunidade local, tornando-o protagonistas do processo turístico, contribuindo assim com os anseios e as necessidades próprias. Mas é importante ressaltar que os interesses em uma atividade turística se diferem em diversos momentos, por isso cabe aos atores do processo 0 poder de decisão entre as reais necessidades da localidade.

$\mathrm{Na}$ sociedade contemporânea, ainda existem cientistas, pessoas da sociedade organizada e entre outros, que acreditam no turismo como pratica social. Por exemplo nesta linha de pesquisa estão autores como Coriolano (2007), Moesch (2002), e Yazigi (1999), que entendem o turismo como uma participação de diversas interferências sociais, que se aplicam a realidade, ou seja, existe uma visão desmistificada do turismo.

Sendo assim, o turismo passa a ser uma atividade que engloba vários atores no seu processo, que visa entender o comportamento social dos 
envolvidos. Salientando ainda que, a economia faz parte do seu processo, mas não como forma de exploração do esforço humano.

Para então tratar do termo turista, buscamos relacioná-lo ao visitante que opta por conhecer o desconhecido. O turista é motivado pelo desejo de estar em contato com outra localidade, fora do seu cotidiano, "o turista implica em alguém que chega hoje e parte amanhã e que está com um outro desenvolvendo seus interesses através da forma ou unidade da sociação" (SIQUEIRA, 2007). A seguir tratar-se-á com mais especificidade sobre o papel do turista em uma atividade turística.

\section{Turistas}

De modo geral o conceito de turista abrange várias discussões na área, pois considerá-lo como parte de um sistema turístico ou da indústria do turismo, é torná-lo objeto do meio capitalista que rege a sociedade atual.

No entanto o visitante turista está saindo de seu cotidiano e deslocando em busca de um contato com si e com os demais, levando consigo suas bagagens, ou seja, suas experiências e seus conhecimentos. Conforme Siqueira (2007), "o turista encarna uma síntese de forças que se tornam sociais quando rompem o universo individual, fechado em si mesmo, emerge a partir das interações cujas formas sociais resultam dos processos internacionais e comunicacionais que se dão ainda em sua sociedade, durante seu deslocamento rumo à outra sociedade, chegada e retorno".

Portanto, há uma busca de encontros e desencontros, surge então à necessidade de entender o visitante como uma pessoa que é inserida em outra sociedade. Siqueira (2007) rompe o universo individual, e mantém uma ligação com o local, podendo ser por meio da paisagem, da gastronomia, da cultura local, dos aspectos intocáveis e visíveis. Entendendo que o elo entre o estrangeiro e o destino turístico é percebido de diversas formas como: por um contato verbal comunicativo ou pela percepção lúdica do local.

Portanto tornar o turista como parte do universo do anfitrião, nem que seja por tempo indeterminado ou curto, ressaltando que o passeante está intrinsecamente ligado ao tempo e espaço, como Siqueira (2007) aponta que o "turista é aquele que chega hoje, sai amanhã e chega novamente hoje num ir e vir ininterrupto", portanto este elemento do turismo pode ser considerado como alguém que esteja de passagem, a fim de conhecer e interagir com outra sociedade.

Nesta perspectiva a conceituação do visitante, conforme a Conferência das Nações Unidas (1963, apud SIQUEIRA, 2005) aponta que, "o turista seria aquele que permanece mais de 24 horas; e o excursionista, aquele que permanece um tempo inferior a 24 horas", deste modo estas definições de turista e excursionista pertence a uma lógica de capital e influenciando nas relações sociais.

Definir se é turista ou excursionista pela sua quantidade de tempo em um determinado local é exaltar o tempo, é assim seguir uma lógica de capital, ou seja, que o turista é sinônimo de trabalho/dinheiro, pois no sistema vigente as relações são puramente influenciadas pela produção e 
consumo. Ou seja, o passante é considerado como elemento da atividade turística quando disponibiliza mais de 24 horas da sua rotina para o ócio e lazer, se inferior a isto é excursionista, sendo assim as condições de relacionamento, as suas percepções, as motivações e desejos acabam que sendo excluídas e transformadas em fruto da indústria do turismo (MARTINS; MACHADO, 2011).

Neste sentido, podemos perceber as definições de visitante para 0 Estado, o mesmo é visto sobre o viés econômico, e o mesmo se comporta como tal, desta forma apropria-se do território turístico e afastam os elementos fundamentais, como os anseios da comunidade local, as necessidades da localidade e entre outros problemas que os lugares turísticos enfrentam (MARTINS; MACHADO, 2011).

Assim se identificar o passeante como participante ativo no processo turístico e atuando como parte do território logo discernirá o processo turístico como um reprodutor social, que envolve toda sua totalidade. Portanto para explanar as definições de turistas, se faz necessário entender como se forma um território turístico, pois para cada ator do processo emerge uma atuação sobre as localidades (MARTINS; MACHADO, 2011).

Para esse trabalho será adotado o conceito de turista, segundo a Organização Mundial do Turismo (OMT).

\section{Recursos Hídricos como Atrativo do Turismo}

A água é um "bem natural" fundamental para a sobrevivência de vida humana bem como de todas as outras formas de vida, pois não há vida sem água, assim, este recurso quando utilizado pelo Turismo também requer uma série de medidas de conservação e cuidados, pois dependendo da sua qualidade torna-se impróprio para o turismo.

Os problemas de escassez hídrica se atribuem a dois fatores: natural e antrópico. O natural resulta das condições climáticas como as secas prolongadas, ausência da vegetação e tipos de solo e o antrópico provêm dos usos múltiplos e da intensidade de utilização das águas, onde os principais são: abastecimento humano, produção de energia, diluição de esgotos industriais e domésticos, lazer, navegação e a pesca.

Outro fator que agrava a situação dos recursos hídricos no Brasil é que a principal fonte de obtenção de energia elétrica é através de usinas hidrelétricas, causando desta forma enormes alterações no ecossistema, bem como o uso indiscriminado da água para irrigação. O Brasil detém uma das maiores reservas de água doce do mundo (PERTILLE; LANZER, 2006).

Mesmo possuindo toda essa água, algumas regiões brasileiras já sofrem com a escassez. No nordeste e no sudeste brasileiro, por exemplo, as pessoas já estão sentido diariamente, a falta da mesma. Pois o consumo de água não possui um padrão mínimo. O crescimento dos estudos e debates sobre essa problemática no país salienta a necessidade de mudança de comportamento, da sociedade que tem demonstrado pouca preocupação em proteger e conservar esse bem natural finito. 
Com relação ao Turismo em recursos hídricos é uma atividade muito antiga, pois, desde muito tempo as pessoas dirigem-se ao mar, rios e reservatórios para tomar banho e praticar atividades de lazer.

Conforme Brasil (2005), atualmente no Brasil a procura por lugares relacionados com água, como praias, lagos e rios são crescentes, pois se observa que devido a essa demanda muitos lugares que oferecem locais para Turismo e lazer em águas estão se desenvolvendo, em especial os que permitem a balneabilidade e atividades náuticas e aquáticas.

Para facilitar o entendimento do Turismo em recursos hídricos o Ministério do Meio Ambiente (2014) criou três segmentos: "o Turismo e lazer no litoral, o Turismo ecológico e pesca e o Turismo e lazer nos lagos e reservatórios interiores". Dentre esses segmentos, o mais difundido é o Turismo de lazer em praias, no litoral, onde há diversos destinos consolidados como Natal (RN), Porto Seguro (BA), Recife (PE), Florianópolis (SC), entre muitos outros.

O turismo ecológico e a pesca são mais desenvolvidos no Pantanal e na Amazônia, tendo com principais atividades a pesca, o mergulho, as trilhas ecológicas, os passeios de barco, os safáris fotográficos, os esportes de aventura e as visitas em grutas.

O terceiro são os rios, lagos e reservatórios, que tem um fluxo mais regional de visitantes e possibilita o desfrute de inúmeras e belas ilhas e praias que tem em seu percurso, proporcionando deslumbrantes paisagens (BRASIL, 2005). A praia de Luzimangues localizada no lago da UHE de Lajeado está inserida neste segmento, com suas belas paisagens.

As praias em rios e reservatórios vêm sendo cada vez mais utilizadas como áreas de lazer e recreação pelas populações dos municípios onde estão inseridas, atraindo também turistas que buscam opções de lazer mais regionais. Este segmento de turismo e lazer em lagos e reservatórios encontram - se em desenvolvimento em alguns reservatórios brasileiros, porém ainda precisa de uma definição de política e estratégia de uso racional do recurso hídrico como instrumento de ofertar lazer de fácil acesso à sociedade devido ao seu custo (BRASIL, 2005).

\section{Perfil socioeconômico dos visitantes da Praia do Distrito de Luzimangues, Porto Nacional (TO)}

O grupo que participou da pesquisa foi formado por um total de 65 sujeitos, questionados para traçar o perfil do público participante durante a temporada de praia que ocorreu entre os dias 18 de julho a 02 de agosto de 2014, no distrito de Luzimangues, município de Porto Nacional - Tocantins. Ressalta que o questionário foi aplicado pelos alunos do Projeto Rondon-Tur de Porto Nacional - TO.

Para obter a definição do perfil dos visitantes da praia em estudo foram elaboradas perguntas referentes à identificação como: idade, renda, estado civil, sexo e escolaridade. Com relação à idade dos visitantes podemos analisar na Tabela 1, que até 17 anos, corresponde a $2 \%$ dos visitantes; entre 18 e 24 anos, corresponde a 23\%, e de 25 a 31 anos são 29\%, e de 32 
a 38 corresponde a $26 \%$ dos entrevistados, de 39 a 45 anos representa $15 \%$ e sendo $5 \%$ entre 46 e 52 anos. Constatou-se que grande parte da população que frequentou a praia no período de 18 de julho a 02 de agosto de 2014 é considerada jovem com idade entre 18 e 31 anos.

Tabela 1: idade dos visitantes.

Table 1: age of the visitors.

\begin{tabular}{lcc}
\hline \multicolumn{1}{c}{ Qual sua idade } & Total & $\begin{array}{c}\text { Porcentagem } \\
(\%)\end{array}$ \\
\hline Até 17 anos & 1 & $2 \%$ \\
18 a 24 anos & 15 & $23 \%$ \\
25 a 31 anos & 19 & $29 \%$ \\
32 a 38 anos & 17 & $26 \%$ \\
39 a 45 anos & 10 & $15 \%$ \\
46 a 52 anos & 3 & $5 \%$ \\
Mais de 53 anos & ------ & ---- \\
Valor total & 65 & $100 \%$ \\
\hline \multicolumn{4}{c}{ Fonte: Questionário aplicado 08/2014. } \\
\multicolumn{4}{c}{ Source: Questionnaire applied 08/2014. }
\end{tabular}

A renda familiar dos entrevistados foi baseada no salário mínimo do ano de 2014 , que era de 724,00 , onde se observa que $28 \%$ dos sujeitos, possuem uma renda de até $1.356,00$, visto que $29 \%$ possuem uma renda entre $1.357,00$ a $2.712,00$, já $11 \%$ possuem de $2.713,00$ a $4.746,00$, e $2 \%$ de $4.747,00$ a $6.780,00$, de $6.781,00$ a $13.560,00$ representa $6 \%$ dos entrevistados, e acima de $13.561,00$ são $6 \%$ e finalizando $18 \%$ não possuem renda mensal. Ressalta-se que, a maioria dos entrevistados possui uma renda de até três salários mínimos, conforme Tabela 02.

Tabela 2: renda mensal dos visitantes.

Table 2: Monthly income from visitors.

\begin{tabular}{lcc}
\hline $\begin{array}{l}\text { Renda mensal } \\
\text { individual }\end{array}$ & Total & $\begin{array}{c}\text { Porcentagem } \\
(\%)\end{array}$ \\
\hline Até 1356,00 & 18 & $28 \%$ \\
$1.357,00$ a $2.712,00$ & 19 & $29 \%$ \\
$2.713,00$ a $4.746,00$ & 7 & $11 \%$ \\
$4.747,00$ a $6.780,00$ & 1 & $2 \%$ \\
$6.781,00$ a $13.560,00$ & 4 & $6 \%$ \\
Acima de $13.561,00$ & 4 & $6 \%$ \\
$\begin{array}{l}\text { Não possui renda } \\
\text { mensal }\end{array}$ & 12 & $18 \%$ \\
Valor total & 65 & $100 \%$ \\
\hline
\end{tabular}

Fonte: Questionário aplicado 08/2014.

Source: Questionnaire applied 08/2014.

A Tabela 3 corresponde ao estado civil dos frequentadores, onde $46 \%$ são casados, $51 \%$ são solteiros e $3 \%$ são divorciados. Nota-se que os visitantes que mais procurarão a praia de Luzimangues foram os solteiros. 
Tabela 3: estado civil.

Table 3: marital status.

\begin{tabular}{lcc}
\hline $\begin{array}{l}\text { Estado } \\
\text { civil }\end{array}$ & Total & Porcentagem (\%) \\
\hline Casado & 30 & $46 \%$ \\
Solteiro & 33 & $51 \%$ \\
Divorciado & 2 & $3 \%$ \\
Viúvo & 0 & $0 \%$ \\
Valor total & 65 & $100 \%$ \\
\hline
\end{tabular}

Fonte: Questionário aplicado 08/2014.

Source: Questionnaire applied 08/2014.

Com base na pesquisa realizada em Luzimangues, durante a temporada de praia em 2014, 55\% dos entrevistados eram do sexo masculino e $42 \%$ do sexo feminino e $3 \%$ outros, conforme Tabela 4.

Tabela 4: sexo.

Table 4: sex.

\begin{tabular}{lcc}
\hline Sexo & Total & Porcentagem (\%) \\
\hline Masculino & 36 & $55 \%$ \\
Feminino & 27 & $42 \%$ \\
Outros & 2 & $3 \%$ \\
Valor total & 65 & $100 \%$ \\
\hline
\end{tabular}

Fonte: Questionário aplicado 08/2014.

Source: Questionnaire applied 08/2014.

A Tabela 5 corresponde ao grau de escolaridade dos visitantes da praia de Luzimangues, onde $2 \%$ não possuem educação formal, já os visitantes que possui Ensino Fundamental correspondem a 15\%, e com Ensino Médio Incompleto corresponde a 12\%. Já com Ensino Médio Completo corresponde a 40\%, com relação ao Ensino Superior Incompleto representa 17\% e com Ensino Superior Completo corresponde a 12\% dos visitantes. E 2\% com Pós-Graduação completa.

Tabela 5: grau de escolaridade.

Table 5: level of education.

\begin{tabular}{lcc}
\hline Grau de Escolaridade & Total & $\begin{array}{c}\text { Porcentagem } \\
(\%)\end{array}$ \\
\hline Sem Educação Formal & 1 & $2 \%$ \\
Ensino Fund. Primário & 10 & $15 \%$ \\
Ensino Médio completo & 26 & $40 \%$ \\
Ensino Méd. Incompleto & 8 & $12 \%$ \\
Superior Completo & 8 & $12 \%$ \\
Superior Incompleto & 11 & $17 \%$ \\
Pós-Graduação Completa & 1 & $2 \%$ \\
Pós-Graduação & ----- & ---- \\
Incompleta & & \\
Valor total & 65 & $100 \%$ \\
\hline
\end{tabular}

Fonte: Questionário aplicado 08/2014.

Source: Questionnaire applied 08/2014. 
Com base na pesquisa realizada durante a temporada de praia em 2014 no distrito de Luzimangues pôde-se observar na tabela 06, que 35\% dos visitantes eram os residentes. Já $8 \%$ dos visitantes eram os turistas e $57 \%$ eram os excursionistas. Podemos observar na Tabela 6 que os excursionistas, foram os que mais visitaram a praia do distrito de Luzimangues durante a temporada. Pois, grande parte dos excursionistas era das cidades circunvizinhas como: Palmas, Paraíso do Tocantins, Porto Nacional e entre outras. No entanto tinha visitantes de outros estados como Goiás e Pará.

\begin{tabular}{lcc} 
& $\begin{array}{c}\text { Tabela 6: tipo de visitante. } \\
\text { Table 6: type of visitor. }\end{array}$ \\
\hline $\begin{array}{l}\text { Tipo de } \\
\text { visitante }\end{array}$ & Total & Porcentagem (\%) \\
\hline Residente & 23 & $35 \%$ \\
\hline Turista & 05 & $8 \%$ \\
Excursionista & 37 & $57 \%$ \\
Valor total & $\mathbf{6 5}$ & $\mathbf{1 0 0 \%}$ \\
\hline
\end{tabular}

Fonte: Questionário aplicado 08/2014.

Source: Questionnaire applied 08/2014.

Com relação à avaliação da Temporada de Praia em Luzimangues foram avaliados os seguintes itens: limpeza, banheiros, segurança pública, assistência médica, barracas comerciais, ambulâncias, atendimento em geral no evento, barraqueiros, área de camping, área de banho, estacionamento, programação cultural, divulgação da praia, estrutura da praia e organização da praia (Figura 5).

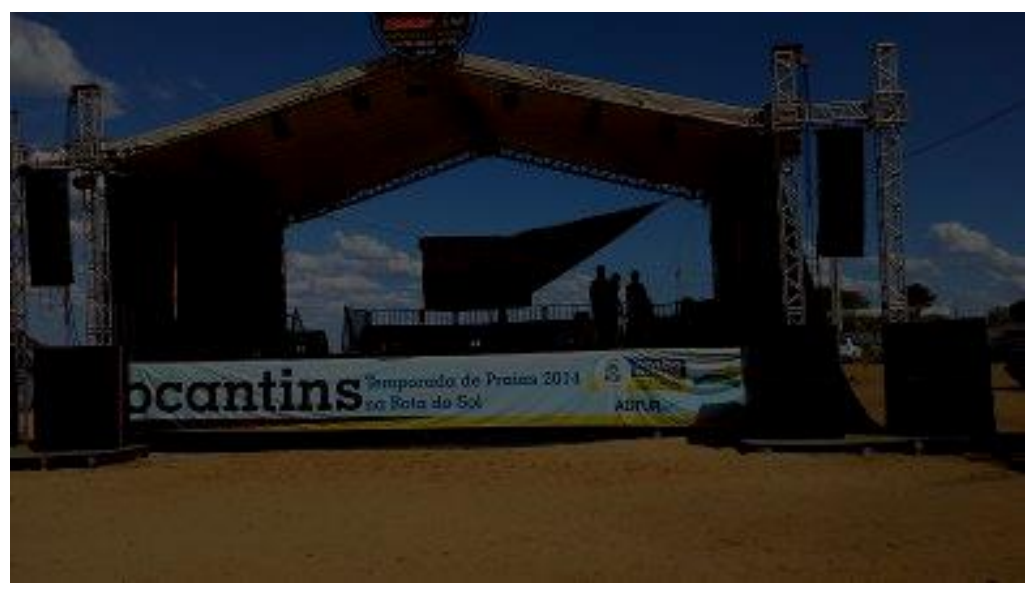

Figura 5: vista parcial do palco de eventos na praia fluvial.

Fonte: Rosane Balsan (2014).

Podemos observar na Tabela 7, que visitantes entrevistados avaliaram a limpeza da praia como regular com $37 \%$, os banheiros foi considerado ruins com $39 \%$, a segurança pública foi avaliada como boa com $32 \%$, à assistência médica foi considerada ruim com $31 \%$, as barracas comerciais foram consideradas boas com $52 \%$, já $40 \%$ dos visitantes avaliaram as ambulâncias como regulares. 
Com relação ao atendimento em geral no evento foi considerado como bom com 49\%, quando perguntado sobre os barraqueiros cerca de $60 \%$ não souberam ou não responderam, já com relação à área de camping e a área banho, cerca de $80 \%$ dos visitantes avaliaram como boa, os estacionamentos e a programação cultural foram consideradas boas com $69 \%$ dos visitantes, já a divulgação da praia foi considerada como regular com $32 \%$, com relação à estrutura e a organização da mesma foi considerada como boa com $100 \%$ dos visitantes. Nota-se que a infraestrutura básica da praia foi considerada boa para grande parte dos visitantes.

Tabela 7: avaliação da temporada de praia segundo os residentes, turistas e excursionistas.

Table 7: Evaluation of the beach season according to residents, tourists and hikers.

\begin{tabular}{|c|c|c|c|c|c|c|c|c|c|c|c|c|}
\hline \multirow{4}{*}{$\begin{array}{r}\text { ITENS } \\
\text { 1-Limpeza }\end{array}$} & \multicolumn{10}{|c|}{ Como o(a) Sr.(a) Avalia a Temporada de Praia em relação a: } & \multirow{3}{*}{\multicolumn{2}{|c|}{$\begin{array}{c}\text { Total Geral } \\
\%\end{array}$}} \\
\hline & \multicolumn{2}{|c|}{ Ótimo } & \multicolumn{2}{|c|}{ Bom } & \multicolumn{2}{|c|}{ Regular } & \multicolumn{2}{|c|}{ Ruim } & \multicolumn{2}{|c|}{$\mathrm{Ns} / \mathrm{Nr}$} & & \\
\hline & Tot & $\%$ & Tot & $\%$ & Tot & $\%$ & Tot & $\%$ & Tot & $\%$ & & \\
\hline & 12 & $18 \%$ & 22 & $34 \%$ & 24 & $37 \%$ & 6 & $9 \%$ & 1 & $2 \%$ & 65 & $100 \%$ \\
\hline 2-Banheiros & 2 & $3 \%$ & 10 & $15 \%$ & 17 & $26 \%$ & 25 & $39 \%$ & 11 & $17 \%$ & 65 & $100 \%$ \\
\hline $\begin{array}{l}\text { 3-Segurança } \\
\text { Pública }\end{array}$ & 6 & $9 \%$ & 21 & $32 \%$ & 18 & $28 \%$ & 12 & $19 \%$ & 8 & $12 \%$ & 65 & $100 \%$ \\
\hline $\begin{array}{l}\text { 4-Assistência } \\
\text { Médica }\end{array}$ & 3 & $5 \%$ & 15 & $23 \%$ & 13 & $20 \%$ & 20 & $31 \%$ & 14 & $21 \%$ & 65 & $100 \%$ \\
\hline $\begin{array}{l}\text { 5-Barracas } \\
\text { Comerciais }\end{array}$ & 5 & $8 \%$ & 34 & $52 \%$ & 13 & $20 \%$ & 6 & $9 \%$ & 7 & $11 \%$ & 65 & $100 \%$ \\
\hline 6-Ambulâncias & 4 & $6 \%$ & 22 & $34 \%$ & 26 & $40 \%$ & 7 & $11 \%$ & 6 & $9 \%$ & 65 & $100 \%$ \\
\hline $\begin{array}{l}\text { 7-At. Geral no } \\
\text { Evento. }\end{array}$ & 5 & $8 \%$ & 32 & $49 \%$ & 16 & $25 \%$ & 6 & $9 \%$ & 6 & $9 \%$ & 65 & $100 \%$ \\
\hline 8-Barraqueiro & 3 & $4 \%$ & 5 & $8 \%$ & 11 & $17 \%$ & 7 & $11 \%$ & 39 & $60 \%$ & 65 & $100 \%$ \\
\hline $\begin{array}{l}\text { 9-Área de } \\
\text { Camping }\end{array}$ & 6 & $9 \%$ & 17 & $26 \%$ & 10 & $15 \%$ & 12 & $19 \%$ & 20 & $31 \%$ & 65 & $100 \%$ \\
\hline $\begin{array}{l}\text { 10-Área de } \\
\text { Banho }\end{array}$ & 8 & $12 \%$ & 35 & $54 \%$ & 13 & $20 \%$ & 6 & $9 \%$ & 3 & $5 \%$ & 65 & $100 \%$ \\
\hline $\begin{array}{l}\text { 11-Estaciona } \\
\text { mento }\end{array}$ & 3 & $4 \%$ & 20 & $31 \%$ & 13 & $20 \%$ & 7 & $11 \%$ & 22 & $34 \%$ & 65 & $100 \%$ \\
\hline $\begin{array}{l}\text { 12Programação } \\
\text { Cultural }\end{array}$ & 4 & $6 \%$ & 25 & $38 \%$ & 18 & $28 \%$ & 9 & $14 \%$ & 9 & $14 \%$ & 65 & $100 \%$ \\
\hline $\begin{array}{l}\text { 13-Divulgação } \\
\text { da Praia }\end{array}$ & 2 & $3 \%$ & 20 & $31 \%$ & 21 & $32 \%$ & 13 & $20 \%$ & 9 & $14 \%$ & 65 & $100 \%$ \\
\hline $\begin{array}{l}\text { 14-Estrutura da } \\
\text { Praia }\end{array}$ & 4 & $6 \%$ & 30 & $46 \%$ & 20 & $31 \%$ & 6 & $9 \%$ & 5 & $8 \%$ & 65 & $100 \%$ \\
\hline $\begin{array}{l}\text { 15-Organização } \\
\text { da Praia }\end{array}$ & 4 & $6 \%$ & 35 & $54 \%$ & 16 & $25 \%$ & 7 & $11 \%$ & 3 & $4 \%$ & 65 & $100 \%$ \\
\hline
\end{tabular}

Fonte: Questionário aplicado 08/2014.

Source: Questionnaire applied 08/2014.

No que se refere à infraestrutura básica e turística no distrito de Luzimangues, município de Porto Nacional, foram avaliados os seguintes itens: a rodoviária, restaurante, meios de hospedagem, transporte intermunicipal, posto médico e diversão noturna. 
Pôde-se observar na Tabela 8 que $28 \%$ dos visitantes avaliaram a rodoviária como boa, $34 \%$ avaliaram os restaurantes como bons, com relação aos meios de hospedagem $34 \%$ consideraram bons, $32 \%$ dos visitantes avaliaram os meios de transporte intermunicipal como bons e com relação à diversão noturna e aos postos médicos $66 \%$ não souberam ou não responderam. Contatou-se que a infraestrutura básica do distrito foi considerada boa para grande parte dos visitantes.

Tabela 8: avaliação da infraestrutura do distrito de Luzimangues segundo os residentes, turistas e excursionistas.

Table 8: Evaluation Luzimangues district infrastructure according to residents, tourists and hikers.

\section{Como o(a) Sr.(a) Avalia a infraestrutura básica e turística do município em relação a:}

\begin{tabular}{|c|c|c|c|c|c|c|c|c|c|c|c|c|}
\hline ITENS & \multicolumn{2}{|c|}{ Ótimo } & \multicolumn{2}{|c|}{ Bom } & \multicolumn{2}{|c|}{ Regular } & \multicolumn{2}{|c|}{ Ruim } & \multicolumn{2}{|c|}{$\mathrm{Ns} / \mathrm{Nr}$} & \multicolumn{2}{|c|}{ Total Geral } \\
\hline & Tot & $\%$ & Tot & $\%$ & Tot & $\%$ & Tot & $\%$ & Tot & $\%$ & & $\%$ \\
\hline $\begin{array}{l}\text { Rodoviár } \\
\text { ia }\end{array}$ & 6 & $9 \%$ & 18 & $28 \%$ & 14 & $22 \%$ & 10 & $15 \%$ & 17 & $26 \%$ & 65 & $100 \%$ \\
\hline $\begin{array}{l}\text { Restaura } \\
\text { nte }\end{array}$ & 5 & $8 \%$ & 22 & $34 \%$ & 15 & $23 \%$ & 8 & $12 \%$ & 15 & $23 \%$ & 65 & $100 \%$ \\
\hline $\begin{array}{l}\text { Meios de } \\
\text { Hospeda } \\
\text { gem }\end{array}$ & 7 & $11 \%$ & 22 & $34 \%$ & 12 & $18 \%$ & 10 & $15 \%$ & 14 & $22 \%$ & 65 & $100 \%$ \\
\hline
\end{tabular}

\begin{tabular}{lcccccccccccc}
$\begin{array}{l}\text { Transpor } \\
\text { te } \\
\text { Intermuni } \\
\text { cipal }\end{array}$ & 5 & $8 \%$ & 21 & $32 \%$ & 10 & $15 \%$ & 9 & $14 \%$ & 20 & $31 \%$ & 65 & $100 \%$ \\
$\begin{array}{l}\text { Posto } \\
\text { Médico }\end{array}$ & 6 & $9 \%$ & 15 & $23 \%$ & 14 & $22 \%$ & 8 & $12 \%$ & 22 & $34 \%$ & 65 & $100 \%$ \\
$\begin{array}{l}\text { Diversão } \\
\text { Noturna }\end{array}$ & 5 & $8 \%$ & 18 & $28 \%$ & 13 & $20 \%$ & 8 & $12 \%$ & 21 & $32 \%$ & 65 & $100 \%$ \\
\hline
\end{tabular}

Fonte: Questionário aplicado 08/2014.

Source: Questionnaire applied 08/2014.

\section{Considerações Finais}

Com a presente pesquisa foi possível observar que, no distrito de Luzimangues, município de Porto Nacional, Estado do Tocantins, o turismo, encontra-se em desenvolvimento, em relação à praia.

Ao término da análise dos resultados dos questionários aplicados para a elaboração deste texto, observa-se que os padrões de respostas dos visitantes da praia foram semelhantes.

Ao estudar o perfil socioeconômico dos visitantes, constatou-se que os tipos de visitante, que mais frequentaram a praia de Luzimangues durante a temporada em 2014, foram os excursionistas. Ao tentar discutir, no questionário sobre a infraestrutura da praia e do distrito, pode-se verificar que grande parte dos frequentadores considerou como boas.

No que se referem à origem, dos frequentadores, os excursionistas e os turistas em sua maioria são oriundos da capital Palmas, outra parcela significativa são os residentes $e$ os frequentadores das cidades circunvizinhas e alguns de outros estados do Brasil. 
Com relação às formas de lazer no Estado do Tocantins, destacam-se as "praias fluviais", que se caracterizam pelo uso das margens dos rios para a implantação de uma infraestrutura, por parte do Poder Público municipal ou estadual, composta por bares, restaurantes, banheiros, palcos para shows, área de Camping e entre outras, a fim de propiciar um melhor entretenimento aos visitantes.

Sendo assim, a praia de Luzimangues pode ser considerada como uma praia fluvial, pois apresenta as características mencionadas acima.

Naturalmente, há que se conscientizar o poder público municipal para que direcione mais recursos para melhorar a infraestrutura local, e a população em geral e os turistas, da importância da preservação dos recursos naturais e do meio ambiente, o que deve ser feito com a efetivação de programas de educação ambiental nas escolas, em seus diversos níveis, e palestras direcionadas aos visitantes, através de visitas orientadas aos pontos turísticos.

\section{Referências bibliográficas}

BRASIL. Ministério do Meio Ambiente. Agência Nacional de Águas. Turismo e o lazer e sua interface com o setor de recursos hídricos. Brasília, DF: ANA, 2005. (Cadernos de Recursos Hídricos, v. 5)

BRASIL. Ministério do Meio Ambiente. Plano Nacional de Resíduos Sólidos. Brasília: MMA, 2004. (Versão preliminar para consulta pública).

BRITO, E.R. Avaliação Qualitativa de Impactos Ambientais Decorrentes do Empreendimento Denominado "Praias Fluviais", no Estado de Tocantins. Dissertação de Mestrado (Curso de Ciência Florestal). Universidade Federal de Viçosa. Viçosa-MG, 2001.

BRITO, E. R. et al. Perfil Ambiental do Empreendimento Denominado de "Praias Fluviais", Estado do Tocantins. Árvore, Viçosa-MG, v.26, n.3, 2002.

CORIOLANO, L.N.M.T. Epistemologia da análise do discurso no turismo. Caderno Virtual de Turismo, n. 16, p. 39-45, 2005.

GHIRALDELLIA, K.J. Praia do Excursionismo ao Turismo. Estudo de Caso: Praia Grande - SP. Monografia do curso de Turismo, Centro Universitário Salesiano de São Paulo - Centro Unisal. Americana, São Paulo, 2001.

INSTITUTO BRASILEIRO DE GEOGRAFIA E ESTATÍSTICA. Censo demográfico, 2010. Rio de Janeiro: IBGE, 2013. Disponível em: <http://www.ibge.gov.br>. Acesso em: 12 fev. 2015.

LEONEL, W. Turismo e desenvolvimento local: o misticismo como manifestação em Boa Sorte - MS. Campo Grande, MS: Universidade Católica Dom Bosco, 2002. Disponível em:

$<$ http://site.ucdb.br/public/md-dissertacoes/7906-turismo-e-desenvolvimento-

local-o-misticismo-como-manifestacao-em-boa-sorte-ms.pdf>. Acesso em: 20 mar. 2015.

MARTINS, B.M L.; MACHADO, A B. Caracterização do perfil dos turistas do Bairro de Maresias São Sebastião (SP) quanto às origens e as motivações. VI ENCONTRO DE PRODUÇÃO CIENTÍFICA E TECNOLÓGICA, VI. Anais... São Paulo: FAPESP, 2011. 
MARQUES, E.E. et al. As praias da Graciosa e de Porto Real: um estudo perceptivo. As praias da Graciosa e de Porto Real: um estudo perceptivo. In: NAVAL, L.P.; PARENTE, T.G. (Org.). Impactos socioambientais: o desafio da construção de hidrelétricas. Goiânia: Cânone Editorial, 2009, v. 1, p. 89-104.

MASSARUTTO, R.C; VIEIRA, M.L. Turismo de segunda residência: a Geografia como percepção espacial, e o turismo como atividade modificadora do espaço. (s. I..: s. n., 2005).

MOESCH, M. A produção do saber turístico. São Paulo: Contexto, 2002.

PERTILLE, I. LANZER, R. Turismo em reservatórios de hidrelétricas: uma reflexão sobre o múltiplo uso e os possíveis impactos ambientais. SEMINÁRIO DE PESQUISA EM TURISMO DO MERCOSUL, IV. Anais... Caxias do Sul, RS: Universidade de Caxias do Sul, 2006.

PINTO, L.M.C. Luzimangues: uma "nova cidade" na periferia de Palmas? Palmas, TO: Arquitextos,2014.

SIQUEIRA, D. História Social do Turismo. Brasília, DF: Vieira, 2005.

SIQUEIRA, E.D. O turista, o estrangeiro e o viajante: notas para uma sociologia do turismo e da viagem. In: CONGRESSO BRASILEIRO DE CIÊNCIAS DA COMUNICAÇÃO, XXX. Anais... Santos, SP: INTERCOM, 2007. v. 1. p. 1-15.

SOUSA, W.J. Os Discursos e o Desenvolvimento Local do Turismo: um diálogo no município de Porto Nacional (TO). Dissertação (Curso de Geografia), Universidade Federal do Tocantins - UFT. Porto Nacional, 2012.

YAZIGI, E. Turismo: uma esperança condicional. São Paulo: Global, 1999.

Maria do Bonfim Cavalcante Santana: Universidade Federal do Tocantins, Porto Nacional, TO, Brasil.

E-mail: maria_loirinha11@hotmail.com

Link para o currículo Lattes: http://lattes.cnpq.br/7255672090470529

Rosane Balsan: Universidade Federal do Tocantins, Porto Nacional, TO, Brasil.

E-mail: rosanebalsan@hotmail.com

Link para o currículo Lattes: http://lattes.cnpq.br/1521061622984234

Data de submissão: 03 de março de 2015

Data de recebimento de correções: 29 de outubro de 2015

Data do aceite: 29 de outubro de 2015

Avaliado anonimamente 